\title{
Pseudo-Kappa Light Chain Restricted Hematogones in Patients Receiving Daratumumab
}

\author{
Daratumumab Alan Hastalarda Yalancı-Kappa Hafif Zincir Sınırlı Hematogonlar
}

\author{
(D) Hamza Tariq ${ }^{1}$, (D) Urooj Zahra² \\ ${ }^{1}$ Rush University Medical Center, Chicago, Illinois, USA \\ ${ }^{2}$ Doctors Hospital and Medical Center, Punjab, Pakistan
}

\section{To the Editor,}

Daratumumab is a therapeutic anti-CD38 monoclonal antibody that is commonly administered for patients with multiple myeloma as a single agent or in combination with other myeloma therapies. While daratumumab has shown significant survival benefits, its ability to confound and interfere with several routine laboratory tests including blood compatibility testing [1], paraprotein quantification via serum protein electrophoresis and serum immunofixation [2], and minimal residual disease testing for plasma cell neoplasms by flow cytometric immunophenotyping is well known [3]. A relatively less recognized potential technical interference caused by daratumumab in the setting of flow cytometry is artifactual kappa light chain restriction in hematogones.

We describe the results of flow cytometric immunophenotyping performed on a bone marrow aspirate from a patient with a history of IgG kappa multiple myeloma treated with daratumumab to illustrate this potential technical pitfall. The patient was treated with seven cycles of Ienalidomide, bortezomib, and dexamethasone (RVD) induction therapy following his diagnosis, resulting in a partial response. He additionally received six cycles of Velcade (bortezomib), daratumumab, and methylprednisolone. A follow-up bone marrow biopsy was performed 2 weeks after the last infusion to assess disease status. Flow cytometric immunophenotyping performed on this bone marrow specimen showed a small polytypic plasma cell population with no immunophenotypic abnormalities except the anticipated CD38 negativity due to the effect of daratumumab (Figure 1A, red population). In addition, we detected a CD38-negative hematogone population with apparent kappa surface light chain restriction (Figures 1A-1D, blue population). Extensive immunophenotypic and morphologic assessment of the bone marrow showed no evidence of an abnormal precursor or mature B-cell population. This mystery was eventually solved when the kappa light chain restriction

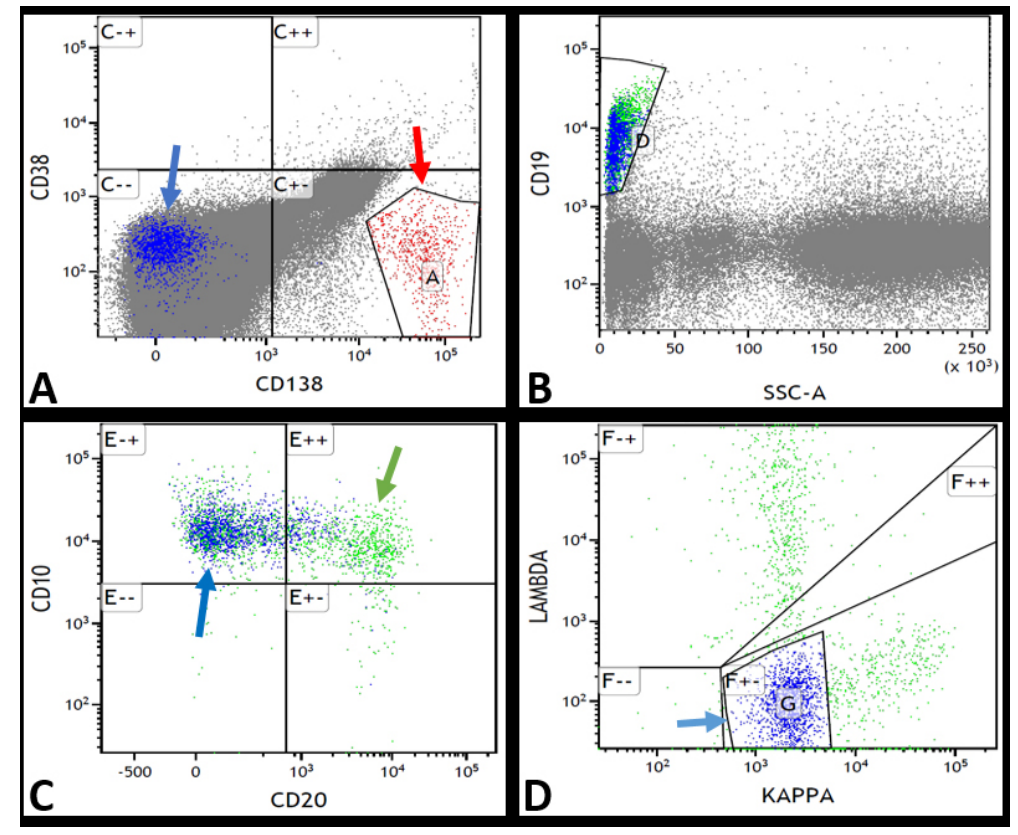

Figure 1. No immunophenotypic abnormalities were observed in the plasma cells except the anticipated CD38 negativity due to the effect of daratumumab (red population, A). A CD38-negative hematogone population with apparent kappa surface light chain restriction was observed (blue population, A-D). 
disappeared upon intracytoplasmic light chain staining. False surface kappa light chain restriction in hematogones in patients receiving daratumumab has been reported before and is believed to be due to the cross-reactivity of the fluorochrome-labeled anti-kappa antibody with daratumumab bound to CD38 on the surface of the hematogones [4].

Hematogones are benign B-cell precursors that are frequently expanded in post-chemotherapy bone marrows. Unlike their malignant counterparts (B lymphoblasts), hematogones show a very predictable pattern of maturation on flow cytometry. Earlystage and intermediate-stage hematogones show uniformly bright CD38 positivity and lack surface light chain expressions, while late-stage hematogones are moderately CD38-positive and show polytypic expression for surface light chains [5]. Since daratumumab is an anti-CD38 IgG kappa monoclonal antibody, it binds to the CD38 on the hematogones and cross-reacts with the fluorochrome-labeled anti-kappa, resulting in false kappa restriction. Pathologists and flow cytometry technologists need to be aware of this technical pitfall to avoid misdiagnosis as a precursor or a mature CD10-positive B-cell neoplasm. Clues to potential daratumumab interference in the setting of flow cytometry are CD38-negative plasma cells and hematogones, kappa surface light chain expression in otherwise phenotypically unremarkable early-stage to intermediate-stage hematogones, and resolution of pseudo-restriction upon intracytoplasmic staining for kappa and lambda light chains.

Keywords: Daratumumab, Hematogones, Kappa, Cytometry, Artifactual
Anahtar Sözcükler: Daratumumab, Hematogonlar, Sitometri, Yapay

Informed Consent: This is not an experimental, clinical, or drug study. No patient identifiers are used. Informed consent is not applicable.

\section{Authorship Contributions}

Concept: H.T., U.Z.; Design: H.T., U.Z.; Data Collection or Processing: H.T., U.Z.; Analysis or Interpretation: H.T., U.Z.; Literature Search: H.T., U.Z.; Writing: H.T., U.Z.

Conflict of Interest: No conflict of interest was declared by the authors.

Financial Disclosure: The authors declared that this study received no financial support.

\section{References}

1. Deneys V, Thiry C, Frelik A, Debry C, Martin B, Doyen C. Daratumumab: Therapeutic asset, biological trap! Transfus Clin Biol 2018;25:2-7.

2. Moore LM, Cho S, Thoren KL. MALDI-TOF mass spectrometry distinguishes daratumumab from M-proteins. Clin Chim Acta 2019;492:91-94.

3. Nooka AK, Kaufman JL, Hofmeister CC, Joseph NS, Heffner TL, Gupta VA, Sullivan HC, Neish AS, Dhodapkar MV, Lonial S. Daratumumab in multiple myeloma. Cancer 2019;125:2364-2382.

4. Jiang XY, Luider J, Shameli A. Artifactual kappa light chain restriction of marrow hematogones: a potential diagnostic pitfall in minimal residual disease assessment of plasma cell myeloma patients on daratumumab. Cytometry B Clin Cytom 2020;98:68-74.

5. Chantepie SP, Cornet E, Salaün V, Reman O. Hematogones: an overview. Leuk Res 2013;37:1404-1411.

๑Copyright 2022 by Turkish Society of Hematology

Turkish Journal of Hematology, Published by Galenos Publishing House

口:5 Address for Correspondence/Yazışma Adresi: Hamza Tariq, M.D., Rush University Medical Center, Chicago,

IItinois, USA

Phone : +90 312-942-8026

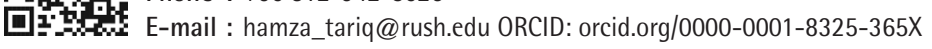

Received/Geliş tarihi: August 20, 2021 Accepted/Kabul tarihi: November 16, 2021

DOI: 10.4274/tjh.galenos.2021.2021.0480 